\title{
Alterações microbianas no solo durante o ciclo do milho nos sistemas plantio direto e convencional
}

\author{
Luciano Kayser Vargas ${ }^{(1)}$, Pedro Alberto Selbach(2) e Enílson Luiz Saccol de Sá(2)
}

(1)Fundação Estadual de Pesquisa Agropecuária, Rua Gonçalves Dias 570, CEP 90130-060 Porto Alegre, RS. E-mail: luciano-kayser@fepagro.rs.gov.br (2)Universidade Federal do Rio Grande do Sul, Fac. de Agronomia, dep. de Solos, Caixa Postal 776, CEP 90001-970 Porto Alegre, RS. E-mail: pedro.selbach@ufrgs.br, enilson.sa@ufrgs.br

\begin{abstract}
Resumo - A disponibilidade de resíduos de aveia-preta, com relação C:N elevada, resulta em imobilização microbiana de nitrogênio no solo, exigindo cuidados no manejo da adubação nitrogenada da cultura subseqüente. O objetivo deste trabalho foi avaliar as alterações na estrutura da comunidade microbiana ao longo do ciclo do milho, na presença de resíduos de aveia-preta e da aplicação de nitrogênio. Foram coletadas amostras de um Argissolo Vermelho distrófico no dia da semeadura do milho e 46, 62, 88 e 112 dias após a semeadura. O nitrogênio foi aplicado 25 dias e 49 dias após a semeadura. As alterações na comunidade microbiana foram avaliadas mediante relações entre carbono $(\mathrm{C})$ e nitrogênio $(\mathrm{N})$, nitrogênio reativo com ninidrina (N-Nin) e carboidratos $(\mathrm{CHO})$ da biomassa microbiana, além da análise do rDNA fúngico e bacteriano. As diferenças na composição da comunidade microbiana, reveladas pela análise do rDNA, relacionaram-se mais com as relações C:N e C:N-Nin do que com a relação C:CHO. As relações C:N-Nin e C:N e as avaliações do rDNA mostraram um predomínio inicial de população fúngica. Com a aplicação de $\mathrm{N}$, a população bacteriana tornou-se preponderante $\mathrm{e}$, ao final do ciclo do milho, retornou para uma condição semelhante à inicial.
\end{abstract}

Termos para indexação: biomassa microbiana, PCR, preparos de solo, imobilização de nitrogênio, Zea mays.

\section{Microbial changes in soil during a maize crop season in no-till and conventional systems}

\begin{abstract}
The availability of black oat residues, with high C:N ratio, leads to microbial immobilization of soil nitrogen, demanding special strategies to supply nitrogen to subsequent crops. The objective of this work was to evaluate shifts in microbial community structure due to the availability of black oat residues and nitrogen applications during the corn growing season. Soil (Paleudult) samples were collected on the day of the corn seeding and after 46, 62, 88 and 112 days. Nitrogen fertilizer was applied 25 and 49 days after corn seeding. Changes in microbial community were assessed by microbial biomass carbon $(\mathrm{C})$ and nitrogen $(\mathrm{N})$, ninhydrinreactive $\mathrm{N}(\mathrm{N}-\mathrm{Nin})$ and carbohydrates $(\mathrm{CHO})$ ratios, besides the analysis of the rDNA of bacteria and fungi. Changes in microbial community shown by rDNA analysis were more related to $\mathrm{C}: \mathrm{N}$ and $\mathrm{C}: \mathrm{N}-\mathrm{Nin}$ ratios than to $\mathrm{C}: \mathrm{CHO}$ ratio. The $\mathrm{C}: \mathrm{N}$ and $\mathrm{C}: \mathrm{N}-\mathrm{Nin}$ ratios and the analysis of the rDNA showed that microbial community was predominantly fungal at the beginning of the evaluation period. After nitrogen application, the bacterial population became preponderant and, at the end of the evaluation period, microbial community turned back to a composition similar to the initial.
\end{abstract}

Index terms: microbial biomass, PCR, soil tillage, nitrogen immobilization, Zea mays.

\section{Introdução}

O sistema plantio direto caracteriza-se pela manutenção do solo coberto durante todo o ano, o que faz com que as plantas de cobertura de outono/inverno assumam um papel fundamental neste sistema de manejo. Entre várias espécies, a aveia-preta tem sido a mais utilizada como planta de cobertura na Região Sul do Brasil, por sua produção elevada de fitomassa, seu cus- to, facilidade de obtenção de sementes e sua rusticidade (Heinrichs et al., 2001).

Embora eficiente como cobertura, controlando a erosão e adicionando carbono orgânico ao solo, a aveiapreta produz resíduos com relação C:N elevada, o que resulta na imobilização de $\mathrm{N}$ por parte da microbiota durante a sua decomposição (Janssen, 1996). Com isso, há uma diminuição na disponibilidade de $\mathrm{N}$ para a cultura seguinte, exigindo cuidados no manejo da adubação 
nitrogenada em culturas como o milho. Embora a recomendação da adubação nitrogenada seja feita a partir de critérios validados experimentalmente no sistema convencional, têm sido propostas alternativas, tais como a antecipação da adubação nitrogenada no sistema plantio direto (Ceretta et al., 2002), a qual considera a ocorrência da imobilização microbiana do nitrogênio. Porém, a comunidade microbiana, agente do processo de imobilização, não é freqüentemente estudada.

A comunidade microbiana do solo é influenciada pela temperatura, umidade e aeração do solo, disponibilidade de nutrientes e pelos substratos orgânicos. Estes fatores, por sua vez, podem ser modificados pelo sistema de manejo, em razão da forma como os resíduos das culturas anteriores são depositados e do grau de revolvimento do solo (Vargas \& Scholles, 2000).

Com o sistema plantio direto, os resíduos são mantidos na superfície e o revolvimento limita-se à linha de semeadura. A manutenção dos resíduos culturais na superfície altera o regime térmico do solo, conserva a sua umidade, diminui as perdas de solo por erosão e aumenta a proteção física da matéria orgânica no interior dos agregados (Bayer \& Mielniczuk, 1997). Com isso, o sistema plantio direto promove um aumento da matéria orgânica junto à superfície do solo. O sistema convencional, por sua vez, caracteriza-se por uma distribuição mais uniforme da matéria orgânica e dos nutrientes no perfil, em virtude da inversão da camada superficial e da incorporação dos resíduos durante a aração (Alvarez et al., 1995).

A biomassa e a atividade microbiana seguem o mesmo padrão de distribuição dos resíduos e da matéria orgânica ao longo do perfil do solo (Alvarez et al., 1995). $\mathrm{O}$ acúmulo de matéria orgânica e de nutrientes favorece o crescimento e a atividade microbiana na camada superficial do solo sob sistema plantio direto (Vargas \& Scholles, 2000). Portanto, o aumento da biomassa microbiana acarreta uma maior imobilização de nitrogênio (Vargas \& Scholles, 1998).

O efeito dos sistemas de manejo sobre a microbiota, porém, não se restringe a aspectos quantitativos, como as alterações na biomassa. Também a composição da comunidade microbiana pode ser alterada, pois os grupos microbianos podem ser afetados diferentemente pelas práticas de manejo. O preparo freqüente do solo, por exemplo, pode ocasionar o rompimento físico de hifas (Calderón et al., 2001), prejudicando a população fúngica. Assim, a população fúngica seria favorecida no sistema plantio direto, podendo mesmo ser predomi- nante. No entanto, Allison \& Killham (1988) constataram um aumento da população fúngica após a incorporação de palha de cevada, indicando que o estímulo à população fúngica deve-se mais à qualidade do resíduo do que à sua forma de disposição no solo.

A estrutura da comunidade microbiana tem reflexos diretos no potencial de imobilização de $\mathrm{N}$, pois depende da relação $\mathrm{C}: \mathrm{N}$ dos microrganismos, que varia entre espécies e grupos microbianos. A população bacteriana apresenta uma relação $\mathrm{C}: \mathrm{N}$ mais baixa e um maior potencial de imobilização de $\mathrm{N}$ do que a população fúngica (Mary et al., 1996). Desse modo, práticas que favoreçam a população bacteriana, como o aumento da disponibilidade de nitrogênio (Garcia \& Rice, 1994), reduzirão a relação $\mathrm{C}: \mathrm{N}$ da biomassa microbiana, enquanto práticas que beneficiem a população fúngica produzirão efeito contrário.

No sistema plantio direto, há maior disponibilidade de compostos nitrogenados na camada superficial do solo (Salinas-Garcia et al., 1997), o que poderia estimular a população bacteriana. Aslam et al. (1999) encontraram relações C:N menores na biomassa microbiana em solo sob plantio direto em duas das três avaliações realizadas pelos autores. Estes resultados indicam que, ao menos em determinados períodos, a biomassa microbiana no sistema plantio direto pode ser predominantemente bacteriana, apresentando uma relação $\mathrm{C}: \mathrm{N}$ menor do que a do sistema convencional, o que resultaria em um maior potencial de imobilização de nitrogênio.

O objetivo deste trabalho foi avaliar as alterações na estrutura da comunidade microbiana, ao longo do ciclo do milho, na presença de resíduos de aveia-preta e da aplicação de nitrogênio, em solo sob plantio direto e convencional.

\section{Material e Métodos}

O trabalho foi realizado num Argissolo Vermelho distrófico, textura franco-argilosa (Paleudult), cultivado com a sucessão das gramíneas aveia-preta/milho, sob os sistemas plantio direto ou convencional. As amostras de solo foram coletadas de um experimento com tratamentos de preparos de solo e de sistemas de culturas, localizado na Estação Experimental Agronômica da Universidade Federal do Rio Grande do Sul (EEA/UFRGS). Detalhes sobre as características do solo e o histórico do experimento encontram-se em Bayer \& Mielniczuk (1997). 
Anteriormente à semeadura do milho, efetuou-se a rolagem da aveia-preta, em 31/8/1999, cuja relação C:N era de 59. O preparo convencional do solo foi realizado em 13/9/1999 e a semeadura do milho, em 23/9/1999, em ambos os sistemas. A adubação nitrogenada de cobertura (uréia), perfazendo um total $180 \mathrm{~kg} \mathrm{ha}^{-1}$, foi aplicada a lanço em duas doses: $60 \mathrm{~kg} \mathrm{ha}^{-1}$ aos 25 dias e $120 \mathrm{~kg} \mathrm{ha}^{-1}$ aos 49 dias após a semeadura do milho. Após cada aplicação, procedeu-se uma irrigação por aspersão equivalente a $20 \mathrm{~mm}$.

Foram coletadas amostras compostas de cinco subamostras na camada de $0-5 \mathrm{~cm}$, em cinco épocas ao longo do ciclo do milho, ou seja, no dia da semeadura do milho e 46, 62, 88 e 112 dias após. As amostras foram mantidas intactas, acondicionadas em sacos de plástico e transportadas em caixas de isopor com gelo até o laboratório, quando foram homogeneizadas com o uso de peneira com malha de $4 \mathrm{~mm}$. A seguir, parte das amostras foi pesada para as avaliações dos constituintes da biomassa microbiana, enquanto o restante foi armazenado em congelador a $-10^{\circ} \mathrm{C}$ até o momento em que foram efetuadas as demais análises. As alterações na comunidade microbiana ao longo do ciclo do milho foram estimadas por meio das relações entre os constituintes da biomassa microbiana e da análise do rDNA de fungos e de bactérias.

No estabelecimento das relações entre seus constituintes, foram determinadas as quantidades de C (Jenkinson \& Powlson, 1976), N (Brookes et al., 1985), N reativo com ninidrina (N-Nin) (Badalucco et al., 1992) e de carboidratos da biomassa microbiana (Badalucco et al., 1990).

A análise do rDNA de bactérias e de fungos foi feita mediante a extração e purificação do DNA das células microbianas do solo, conforme Selbach (1998), e a posterior amplificação de fragmentos de rDNA. Na amplificação dos fragmentos de rDNA, utilizou-se a técnica da reação em cadeia da polimerase (PCR), com oligonucleotídeos universais específicos para cada um dos grupos microbianos considerados. Os conjuntos de oligonucleotídeos e as condições de reação na amplificação dos fragmentos de rDNA de bactérias e de fungos encontram-se descritas em Felske et al. (1997) e Smit et al. (1999), respectivamente.

Após a amplificação, os produtos de PCR foram carregados em géis de agarose $1,5 \%$, os quais foram submetidos à eletroforese a $80 \mathrm{~V}$ por 75 minutos. Os géis foram fotografados com o sistema Kodak Digital Science EDAS e as imagens foram analisadas quanto à intensi- dade das bandas para estimativa da quantidade de DNA amplificado.

$\mathrm{Na}$ análise dos dados, o delineamento estatístico utilizado foi o de blocos completos casualizados, num esquema fatorial $2 \times 5$, sendo dois sistemas de manejo de solo (plantio direto e convencional) e as cinco épocas de avaliação, com três repetições. As médias foram comparadas pelo teste de Duncan, a 5\% de probabilidade.

\section{Resultados e Discussão}

A relação C:N-Nin da biomassa microbiana apresentou flutuações ao longo do ciclo do milho, as quais foram independentes dos sistemas de manejo, sendo mais elevada no dia da semeadura, decrescendo após a aplicação do nitrogênio (Tabela 1). Ao final do ciclo do milho, tornou a aumentar, mas foi inferior à inicial. Mais do que pelo uso do solo, a relação C:N-Nin é afetada pela composição da comunidade microbiana (Joergensen, 1996). Assim, o decréscimo na relação C:N-Nin seria decorrente de alterações na estrutura da comunidade microbiana induzidas pela adubação nitrogenada, que estimulou a população bacteriana, aumentando a sua proporção em comparação com a fúngica, independentemente do sistema de manejo. Por sua vez, as relações $\mathrm{C}: \mathrm{N}-\mathrm{Nin}$ mais elevadas devem estar relacionadas com a menor disponibilidade de $\mathrm{Ne}$ com o aumento da proporção de fungos na biomassa microbiana (Joergensen et al., 1995).

Como verificado por Salinas-Garcia et al. (1997), o carbono da biomassa microbiana não aumentou após a aplicação de uréia, ao contrário do $\mathrm{N}$ da biomassa microbiana, levando a alterações na relação $\mathrm{C}: \mathrm{N}$ ao longo do ciclo do milho. No dia da semeadura do milho, quando havia maior quantidade de resíduos de aveia-preta, foram observados os valores mais elevados da relação $\mathrm{C}: \mathrm{N}$ da biomassa microbiana em ambos sistemas. A relação C:N da biomassa microbiana geralmente apresenta uma correspondência com a relação C:N dos resíduos orgânicos adicionados ao solo (Gunapala \& Scow, 1998) e é uma resposta à disponibilidade de $\mathrm{N}$ (Salinas-Garcia et al., 1997) e à qualidade dos resíduos. Palhas de cereais são decompostas principalmente por fungos, cuja relação C:N é mais elevada do que bactérias e actinomicetos (Wheatley et al., 1990; Garcia \& Rice, 1994).

Após a aplicação da primeira dose de $\mathrm{N}$, a relação $\mathrm{C}: \mathrm{N}$ da biomassa microbiana decresceu nos dois sistemas, permanecendo inalterada até 88 dias após a seme- 
adura do milho. A mudança na relação $\mathrm{C}: \mathrm{N}$ da biomassa microbiana pode ser o resultado de modificações na sucessão microbiana ou de adaptações no conteúdo interno de fungos (Mary et al., 1996) e está associada com a disponibilidade de nitrogênio. Embora alguns indivíduos ou populações possam ajustar a sua relação $\mathrm{C}: \mathrm{N}$ à do substrato, é pouco provável que toda a comunidade microbiana apresente este comportamento (Wheatley et al., 1990). O mais provável é que a diminuição da relação $\mathrm{C}: \mathrm{N}$ tenha ocorrido em razão do aumento da população bacteriana em resposta às aplicações de uréia (Garcia \& Rice, 1994). A diminuição da relação C:N da biomassa microbiana coincide com a da sua relação C:N-Nin, reforçando a idéia do aumento da população bacteriana.

A relação C: $\mathrm{CHO}$ da biomassa microbiana mostrouse sensível aos manejos, apresentando diferenças entre os tratamentos em todas as avaliações, com exceção da segunda. No dia da semeadura do milho, a proporção de carboidratos na biomassa microbiana foi baixa nos dois sistemas de manejo. Na situação em que os sistemas se encontravam, ou seja, com a disponibilidade de $\mathrm{C}$ alta e a de $\mathrm{N}$ baixa, seria de se esperar uma maior proporção de carboidratos, resultando em relações $\mathrm{C}$ :CHO menores. Relações C:CHO elevadas estão relacionadas com disponibilidades limitadas de $\mathrm{C}$, de $\mathrm{Ne}$ com uma menor presença de fungos (Joergensen et al., 1996).

Na segunda avaliação, a relação C:CHO da biomassa microbiana diminuiu em ambos sistemas. Este resultado não confirma a idéia de que a aplicação da primeira dose de uréia induziu o aumento da proporção de bactérias na biomassa microbiana, levando à diminuição das relações C:N-Nin e C:N. Já na terceira avaliação, ao contrário das avaliações anteriores, a relação C:CHO não conflitou com as relações C:N-Nin e C:N. A relação $\mathrm{C}$ :CHO foi menor no sistema plantio direto, o que indicaria uma maior biomassa fúngica do que no sistema convencional. Porém, a relação C: $\mathrm{CHO}$ aumentou nos dois sistemas em comparação com a avaliação anterior, indicando aumento na população bacteriana, tal como indicado pelas baixas relações C:N-Nin e C:N verificadas nesta avaliação.

Aos 88 dias após a semeadura do milho, a relação C:CHO tornou a diminuir nos dois sistemas. Porém, no sistema plantio direto, a relação foi maior do que no sistema convencional. Na avaliação seguinte, a relação $\mathrm{C}: \mathrm{CHO}$ da biomassa microbiana seguiu a mesma tendência.

Aparentemente, as diferenças observadas entre as relações $\mathrm{C}: \mathrm{N}-\mathrm{Nin}, \mathrm{C}: \mathrm{N}$ e $\mathrm{C}: \mathrm{CHO}$ da biomassa microbiana sugerem que esta última é mais sensível a mudanças na estrutura das comunidades microbianas, em concordância com Joergensen et al. (1996). No entanto, a relação C:CHO da biomassa microbiana pode não ser o indicador mais adequado, pois não depende apenas da predominância de um ou outro grupo microbiano, mas também do metabolismo, do estado de nutrição e da fase de crescimento das células microbianas (Chapman \& Gray, 1981; Badalucco et al., 1990).

Com base na quantificação do DNA presente nos produtos de PCR, verificou-se que a população bacteriana foi mais baixa nos dois sistemas no dia da semeadura do milho (Tabela 2). A população fúngica, ao contrário, foi elevada naquela avaliação, tendo sido maior no sistema convencional. A quantificação dos produtos de PCR confirma o indicado pelas relações $\mathrm{C}: \mathrm{Ne} \mathrm{C}: \mathrm{N}-\mathrm{Nin}$ no dia da semeadura do milho. A presença abundante de resíduos de aveia-preta, ricos em lignina e com relação $\mathrm{C}: \mathrm{N}$ alta, favoreceu a população fúngica em detrimento da população bacteriana. A decomposição

Tabela 1. Carbono $\left(\mathrm{C}, \mathrm{kg} \mathrm{ha}^{-1}\right)$ da biomassa microbiana e relações entre carbono e nitrogênio reativo com ninidrina (C:N-Nin), carbono e nitrogênio $(\mathrm{C}: \mathrm{N})$ e carbono e carboidratos $(\mathrm{C}: \mathrm{CHO})$ da biomassa microbiana do solo nos sistemas plantio direto $(\mathrm{SPD})$ e convencional $(\mathrm{SC})^{(1)}$.

\begin{tabular}{|c|c|c|c|c|c|c|c|}
\hline \multirow{2}{*}{$\begin{array}{l}\text { Dias após } \\
\text { a semeadura }\end{array}$} & \multicolumn{2}{|c|}{$\mathrm{C}$} & \multirow[t]{2}{*}{$\mathrm{C}: \mathrm{N}-\mathrm{Nin}^{(2)}$} & \multicolumn{2}{|c|}{$\mathrm{C}: \mathrm{N}$} & \multicolumn{2}{|c|}{$\mathrm{C}: \mathrm{CHO}$} \\
\hline & SPD & $\mathrm{SC}$ & & SPD & $\mathrm{SC}$ & SPD & $\mathrm{SC}$ \\
\hline 0 & $324 \mathrm{Aa}$ & $154 \mathrm{Ba}$ & $53,5 a$ & $9,7 \mathrm{Aa}$ & $10,9 \mathrm{Aa}$ & $21,1 \mathrm{Aa}$ & $11,9 \mathrm{Bb}$ \\
\hline 46 & 308Aa & $166 \mathrm{Ba}$ & $22,4 \mathrm{c}$ & $7,3 \mathrm{Ab}$ & $7,8 \mathrm{Ab}$ & $9,4 \mathrm{Ac}$ & $6,6 \mathrm{Ac}$ \\
\hline 62 & $257 \mathrm{Ab}$ & $194 \mathrm{Ba}$ & $25,6 b c$ & $7,2 \mathrm{Ab}$ & $7,8 \mathrm{Ab}$ & $14,4 \mathrm{Bb}$ & $20,3 \mathrm{Aa}$ \\
\hline 88 & $192 \mathrm{Ac}$ & $96 \mathrm{Bb}$ & $37,9 \mathrm{~b}$ & $6,5 \mathrm{Ab}$ & $6,8 \mathrm{Ab}$ & $8,8 \mathrm{Ac}$ & $4,1 \mathrm{Bc}$ \\
\hline 112 & $250 \mathrm{Ab}$ & $104 \mathrm{Bb}$ & $39,4 b$ & 7,7Aab & $3,6 \mathrm{Bc}$ & $12,1 \mathrm{Abc}$ & $7,0 \mathrm{Bc}$ \\
\hline
\end{tabular}

${ }^{(1)}$ Médias seguidas por letras distintas diferem entre si, pelo teste de Duncan, a 5\% de probabilidade; letras maiúsculas comparam sistemas de manejo dentro de cada época e letras minúsculas comparam épocas dentro de cada sistema de manejo. ${ }^{(2)}$ Média dos dois sistemas de manejo. 
de palhas de cereais é feita por um consórcio de microrganismos que se alternam durante o processo. Em uma primeira etapa, que dura cerca de sete dias, predominam bactérias que utilizam substratos solúveis em água (Hu \& Bruggen, 1997). Depois, numa segunda etapa, na qual os sistemas se encontravam, predominam fungos que utilizam os polímeros do tecido vegetal a partir da sua capacidade de sintetizar enzimas hidrolíticas (Jensen \& Nybroe, 1999).

Após a aplicação da primeira dose de $\mathrm{N}$, houve um crescimento da população bacteriana em relação à avaliação anterior, que foi mais acentuado no sistema plantio direto. A população fúngica, por sua vez, decresceu no sistema convencional, não diferindo da encontrada no sistema plantio direto, no qual manteve-se inalterada. Estes resultados confirmam que a diminuição das relações C:N e C:N-Nin deveu-se ao aumento da população bacteriana e não a adaptações no metabolismo de fungos em resposta ao aumento da disponibilidade de nitrogênio. A relação C: $\mathrm{CHO}$, ao contrário, não indicou um aumento da população bacteriana nos sistemas de manejo.

Nesta segunda avaliação, foi verificado ainda um aumento na quantidade de $\mathrm{N}$ imobilizado, que resultou em decréscimo da relação $\mathrm{C}: \mathrm{N}$ da biomassa microbiana em ambos sistemas. Estes resultados confirmam a hipótese deste trabalho, uma vez que a aplicação da dose inicial de $\mathrm{N}$ levou a um aumento da sua imobilização, associada ao aumento da população bacteriana e à diminuição da relação $\mathrm{C}: \mathrm{N}$ da biomassa microbiana. A imobilização microbiana do $\mathrm{N}$ e o crescimento da população bacteriana foram mais acentuados no sistema plantio direto, embora a relação $\mathrm{C}: \mathrm{N}$ da biomassa microbiana não tenha diferido entre os dois sistemas.

Tabela 2. Quantidade de DNA em $12 \mu \mathrm{L}$ de produto de PCR de $16 \mathrm{~S}$ rDNA bacteriano e de $18 \mathrm{~S}$ rDNA fúngico nos sistemas plantio direto (SPD) e convencional (SC) ${ }^{(1)}$.

\begin{tabular}{|c|c|c|c|c|}
\hline \multirow{2}{*}{$\begin{array}{l}\text { Dias após } \\
\text { a semeadura }\end{array}$} & \multicolumn{2}{|c|}{ 16S rDNA bacteriano } & \multicolumn{2}{|c|}{ 18S rDNA fúngico } \\
\hline & SPD & $\mathrm{SC}$ & SPD & $\mathrm{SC}$ \\
\hline & \multicolumn{4}{|c|}{ (ng de DNA) } \\
\hline 0 & $46 \mathrm{Ab}$ & $45 \mathrm{Ad}$ & $28 \mathrm{Ba}$ & $36 \mathrm{Aa}$ \\
\hline 46 & $66 \mathrm{Aa}$ & $54 \mathrm{Bc}$ & $31 \mathrm{Aa}$ & $27 \mathrm{Ab}$ \\
\hline 62 & 66Аa & 69Aa & $11 \mathrm{Ab}$ & $9 \mathrm{Ad}$ \\
\hline 88 & 61Aa & $62 \mathrm{Ab}$ & $7 \mathrm{Ab}$ & $12 \mathrm{Ad}$ \\
\hline 112 & $42 \mathrm{Bb}$ & $53 \mathrm{Ac}$ & $14 \mathrm{Ab}$ & $19 \mathrm{Ac}$ \\
\hline
\end{tabular}

${ }^{(1)}$ Médias seguidas por letras distintas diferem entre si, pelo teste de Duncan, a 5\% de probabilidade; letras maiúsculas comparam sistemas de manejo dentro de cada época e letras minúsculas comparam épocas dentro de cada sistema de manejo.
Aos 62 dias após a semeadura do milho, a população bacteriana aumentou no sistema convencional, igualando-se à do sistema plantio direto. Esta, por sua vez, não diferiu da observada na avaliação anterior. Enquanto a população bacteriana atingiu os valores mais elevados, a população fúngica decresceu acentuadamente. A aplicação da segunda dose de uréia favoreceu a população bacteriana em detrimento da população fúngica, mantendo as relações $\mathrm{C}: \mathrm{N}$ e $\mathrm{C}: \mathrm{N}-\mathrm{Nin}$ baixas. A relação C:CHO também refletiu o aumento da população bacteriana, principalmente no sistema convencional. Estes resultados confirmam que a adubação nitrogenada altera a estrutura da comunidade microbiana, favorecendo as bactérias, diminuindo a relação $\mathrm{C}: \mathrm{N}$ e aumentando o potencial de imobilização pela biomassa microbiana.

$\mathrm{Na}$ quarta avaliação, a estrutura da comunidade microbiana permaneceu praticamente inalterada. Houve um decréscimo da população bacteriana no sistema convencional em comparação com a avaliação anterior, mas esta não diferiu da população observada no sistema plantio direto. A população fúngica não se alterou. A proporção de fungos e bactérias na biomassa microbiana parece ter sido semelhante à encontrada aos 62 dias após a semeadura do milho, confirmando o indicado pelas relações $\mathrm{C}: \mathrm{N}$ e $\mathrm{C}: \mathrm{N}-\mathrm{Nin}$. Ao contrário do sugerido pela relação $\mathrm{C}: \mathrm{CHO}$, não houve um aumento da população fúngica.

Na última avaliação, a população bacteriana decresceu em relação à avaliação anterior nos dois sistemas, sendo o decréscimo mais acentuado no sistema plantio direto, no qual a população bacteriana foi inferior à do sistema convencional. A população fúngica aumentou no sistema convencional em relação à avaliação anterior, mas não diferiu da ocorrida no sistema plantio direto. O decréscimo da população bacteriana, no sistema plantio direto, levou ao aumento da relação C:N neste sistema. Já a relação $\mathrm{C}: \mathrm{N}$ mais baixa verificada no sistema convencional parece não ser explicada apenas pelas diferenças nas populações bacterianas dos dois sistemas. Embora a população bacteriana tenha sido superior no sistema convencional em comparação com o plantio direto, a mesma decresceu em relação à observada aos 88 dias após a semeadura do milho, enquanto a população fúngica aumentou. Em comparação com o sistema plantio direto, seria de se esperar uma relação C:N menor no sistema convencional, porém maior do que aquela verificada aos 88 dias após a semeadura do milho neste sistema. A relação $\mathrm{C}: \mathrm{CHO}$ também não é 
esclarecedora, uma vez que aponta um crescimento da população fúngica no sistema convencional. É possível que, nesta avaliação, novas espécies tenham predominado no solo sob sistema convencional, havendo mais do que uma simples alteração nas proporções de fungos e bactérias.

Em geral, as diferenças na composição da comunidade microbiana estiveram mais relacionadas com alterações nas relações $\mathrm{C}: \mathrm{N}$ e C:N-Nin do que com alterações na relação C:CHO. Isto confirma que a relação $\mathrm{C}: \mathrm{CHO}$ da biomassa microbiana não é o indicador mais adequado para monitorar alterações na estrutura da comunidade microbiana, pois é afetada por outros fatores que não apenas a predominância de um ou outro grupo microbiano.

\section{Conclusões}

1. A presença de resíduos de aveia-preta, no início do ciclo do milho, favorece a população fúngica, em ambos sistemas de manejo.

2. A aplicação de nitrogênio favorece a população bacteriana, resultando em diminuição das relações C:N e C:nitrogênio reativo com ninidrina ( $\mathrm{N}-\mathrm{Nin}$ ) da biomassa microbiana e em aumento da imobilização microbiana deste nutriente.

3. A relação C:carboidratos da biomassa microbiana do solo é um indicador menos adequado do que as relações $\mathrm{C}: \mathrm{N}$ e $\mathrm{C}: \mathrm{N}-\mathrm{Nin}$ para monitorar as alterações na composição da comunidade microbiana.

\section{Referências}

ALLISON, M.F.; KILLHAM, K. Response of soil microbial biomass to straw incorporation. Journal of Soil Science, v.39, p.237-242, 1988.

ALVAREZ, R.; DÍAZ, R.A.; BARBERO, N.; SANTANATOGLIA, O.J.; BLOTTA, L. Soil organic carbon, microbial biomass and $\mathrm{CO}_{2^{-}}$ $\mathrm{C}$ production from three tillage systems. Soil and Tillage Research, v.33, p.17-28, 1995.

ASLAM, T.; CHOUDHARY, M.A.; SAGGAR, S. Tillage impacts on soil microbial biomass $\mathrm{C}, \mathrm{N}$ and $\mathrm{P}$, earthworms and agronomy after two years of cropping following permanent pasture in New Zealand. Soil and Tillage Research, v.51, p.103-111, 1999.

BADALUCCO, L.; GELSOMINO, A.; DELL'ORCO, S.; GREGO, S.; NANNIPIERI, P. Biochemical characterization of soil organic compounds extracted by $0,5 \mathrm{M} \mathrm{K}_{2} \mathrm{SO}_{4}$ before and after chloroform fumigation. Soil Biology and Biochemistry, v.24, p.569-578, 1992.

BADALUCCO, L.; NANNIPIERI, P.; GREGO, S.; CIARDI, C. Microbial biomass and anthrone-reactive carbon in soils with different organic matter contents. Soil Biology and Biochemistry, v.22, p.899-904, 1990.
BAYER, C.; MIELNICZUK, J. Características químicas do solo afetadas por métodos de preparo e sistemas de cultura. Revista Brasileira de Ciência do Solo, v.21, p.105-112, 1997.

BROOKES, P.C.; LANDMAN, A.; PRUDEN, G.; JENKINSON, D.S. Chloroform fumigation and the release of soil nitrogen: a rapid direct extraction method to measure microbial biomass nitrogen in soil. Soil Biology and Biochemistry, v.17, p.837-842, 1985.

CALDERÓN, F.J.; JACKSON, L.E.; SCOW, K.M.; ROLSTON, D.E. Short-term dynamics of nitrogen, microbial activity, and phospholipid fatty acids after tillage. Soil Science Society of America Journal, v.65, p.118-126, 2001.

CERETTA, C.A.; BASSO, C.J.; FLECHA, A.M.T.; PAVINATO, P.S; VIEIRA, F.C.B.; MAI, M.E.M. Manejo da adubação nitrogenada na sucessão aveia preta/milho, no sistema plantio direto. Revista Brasileira de Ciência do Solo, v.26, p.163-171, 2002.

CHAPMAN, S.J.; GRAY, T.R.G. Endogenous metabolism and macromolecular composition of Arthrobacter globiformis. Soil Biology and Biochemistry, v.13, p.11-18, 1981.

FELSKE, A.; RHEIMS, H.; WOLTERINK, A.; STACKEBRANDT, E.; AKKERMANS, A.D.L. Ribosome analysis reveals prominent activity of an uncultured member of the class Actinobacteria in grassland soils. Microbiology, v.143, p.2983-2989, 1997.

GARCIA, F.O.; RICE, C.W. Microbial biomass dynamics in tallgrass prairie. Soil Science Society of America Journal, v.58, p.816823,1994

GUNAPALA, N.; SCOW, K.M. Dynamics of soil microbial biomass and activity in conventional and organic farming systems. Soil Biology and Biochemistry, v.30, p.805-816, 1998.

HEINRICHS, R.; AITA, C.; AMADO, T.J.C.; FANCELLI, A.L. Cultivo consorciado de aveia e ervilhaca: relação C:N da fitomassa e produtividade do milho em sucessão. Revista Brasileira de Ciência do Solo, v.25, p.331-340, 2001.

HU, S.; BRUGGEN, A.H.C. van. Microbial dynamics associated with multiphasic decomposition of ${ }^{14} \mathrm{C}$-labeled cellulose in soil. Microbial Ecology, v.33, p.134-143, 1997.

JANSSEN, B.H. Nitrogen mineralization in relation to $\mathrm{C}: \mathrm{N}$ ratio and decomposability of organic materials. Plant and Soil, v.181, p.3945, 1996.

JENKINSON, D.S.; POWLSON, D.S. The effects of biocidal treatments on metabolism in soil - V: A method for measuring soil biomass. Soil Biology and Biochemistry, v.8, p.209-213, 1976.

JENSEN, L.E.; NYBROE, O. Nitrogen availability to Pseudomonas fluorescens DF57 is limited during decomposition of barley straw in bulk soil and in the barley rhizosphere. Applied and Environmental Microbiology, v.65, p.4320-4328, 1999.

JOERGENSEN, R.G. Quantification of the microbial biomass by determining ninhydrin-reactive N. Soil Biology and Biochemistry, v.28, p.301-306, 1996.

JOERGENSEN, R.G.; MUELLER, T.; WOLTERS, V. Total carbohydrates of the soil microbial biomass in $0.5 \mathrm{M} \mathrm{K}_{2} \mathrm{SO}_{4}$ soil extracts. Soil Biology and Biochemistry, v.28, p.1147-1153, 1996.

JOERGENSEN, R.G.; SCHMAEDEKE, F.; WINDHORST, K.; MEYER, B. Biomass and activity of microorganisms in a fuel oil contaminated soil. Soil Biology and Biochemistry, v.27, p.1137$1143,1995$. 
MARY, B.; RECOUS, S.; DARWIS, D.; ROBIN, D. Interactions between decomposition of plant residues and nitrogen cycling in soil. Plant and Soil, v.181, p.71-82, 1996.

SALINAS-GARCIA, J.R.; HONS, F.M.; MATOCHA, J.E. Longterm effects of tillage and fertilization on soil organic matter dynamics. Soil Science Society of America Journal, v.61, p.152-159 ,1997.

SELBACH, P.A. Optimization of a DNA extraction procedure for phylogenetic probe analysis of soil microbial communities. 1998. 127p. Thesis (Ph.D.) - University of Wisconsin, Madison.

SMIT, E.; LEEFLANG, P.; GLANDORF, B.; ELSAS, J.D. van; WERNARS, K. Analysis of fungal diversity in the wheat rhizosphere by sequencing of cloned PCR-amplified genes encoding $18 \mathrm{~S}$
rRNA and temperature gradient gel electrophoresis. Applied and Environmental Microbiology, v.65, p.2614-2621, 1999.

VARGAS, L.K.; SCHOLLES, D. Biomassa microbiana e produção de $\mathrm{C}-\mathrm{CO}_{2}$ e $\mathrm{N}$ mineral de um solo Podzólico Vermelho-Escuro submetido a diferentes sistemas de manejo. Revista Brasileira de Ciência do Solo, v.24, p.35-42, 2000.

VARGAS, L.K.; SCHOLLES, D. Nitrogênio da biomassa microbiana, em solo sob diferentes sistemas de manejo, estimado por métodos de fumigação. Revista Brasileira de Ciência do Solo, v.22, p.411417, 1998.

WHEATLEY, R.; RITZ, K.; GRIFFITHS, B. Microbial biomass and mineral $\mathrm{N}$ transformations in soil planted with barley, ryegrass, pea or turnip. Plant and Soil, v.127, p.157-167, 1990.

Recebido em 11 de fevereiro de 2003 e aprovado em 7 de junho de 2004 